\title{
Analysis and modeling of rail maintenance costs
}

\author{
Amir Ali Bakhshi ${ }^{a}$ and Mohammad Reza Soleymani Yazdi ${ }^{* b}$
}

${ }^{a}$ Faculty of High-Tech and Engineering, Iran University of Industries and Mines, Tehran, Iran

${ }^{b}$ Department of Mechanical Engineering, Imam Hossein University, Tehran, Iran

\begin{tabular}{l}
\hline A R T I C L E I N F O \\
\hline Article history: \\
Received July 10, 2011 \\
Received in Revised form \\
September, 12, 2011 \\
Accepted 25 September 2011 \\
Available online \\
30 September 2011 \\
\hline Keywords: \\
Maintenance engineering \\
Weibull distribution \\
Rail maintenance \\
Railroad industry
\end{tabular}
A B S T R A C T

\begin{abstract}
Railroad maintenance engineering plays an important role on availability of roads and reducing the cost of railroad incidents. Rail is of the most important parts of railroad industry, which needs regular maintenance since it covers a significant part of total maintenance cost. Any attempt on optimizing total cost of maintenance could substantially reduce the cost of railroad system and it can reduce total cost of the industry. The paper presents a new method to estimate the cost of rail failure using different cost components such as cost of inspection and cost of risk associated with possible accidents. The proposed model of this paper is used for a realworld case study of railroad transportation of Tehran region and the results have been analyzed.
\end{abstract}

(C) 2012 Growing Science Ltd. All rights reserved.

\section{Introduction}

Railroad plays an important role on economy of any country especially for developing countries. A serious disruption on rail could create serious accidents such as derailment. Therefore, we need to monitor rail conditions by inspecting different components, lubricating necessary parts or grinding specific portions of rail, carefully. Obviously, there are some costs associated with each part of these components and we need to have a fair balance among them to optimize the cost of maintenance. Inspection cost is a major portion of maintenance, for instance, in European commission; inspection cost is estimated to be between 375 to 850 million dollars per year (Cannon et al., 2003). During the past few decades, there have been many attempts to reduce the cost of maintenance. Hargrove (1985) proposed a model for track degradation based on the failure rate of each component, separately. Ebersohn (1997) introduced a comprehensive method as total productive maintenance by suggesting traffic information, cost, assets and historical data of rail failure. Esveld (2001) investigated various factors influencing rail failure. Cannon et al. (2003) considered hidden effects of using ultrasonic sound waves for detecting rail failure. They showed there are many subsurface of detects on rail, which cannot be detected through regular use of ultrasonic sound waves but they can easily create

* Corresponding author. Tel: +982188003720

E-mail addresses: soleymani63@gmail.com (M.R. Soleymani Yazdi) 
serious damages on rail. Rail wear is another important factor on causing damage on rail system. Jendel (1999) proposed a mathematical model to predict rail wear and introduced suitable lubrication time intervals. Magel and Kalousek (2002) studied different efficient methods for grinding based on the profile of rail. Reddy (2007) in a comprehensive survey analyzed different cost components affecting rail maintenance and suggested some methods for reducing the total cost.

In this paper, we present a new mathematical model to optimize the cost of rail maintenance. The organization of this paper first explains details of the proposed model in section 2 and the results of the implementation of our proposed model are given in section 3. Finally, concluding remarks are given in section 4 to summarize the contribution of this paper.

\section{The proposed model}

In this section, we first explain different methods to determine the rate of failure. There are different factors rate of failure either directly or indirectly such as million gross tones (MGT), axle load, speed, traffic type and density, track curvature and elevation, etc. As the age of rail increases, the rate of failure on rail will also increase proportion to load passes the rail. The rate of failure can be expressed as a Weibull distribution with $\Lambda(m)$ where $m$ represent MGT. Based on this function, there is a higher chance of having crack on a rail when the rail is getting older and MGT increases. In the event we do not see any crack, we will have a higher chance of broken rail. Let $f(m)$ and $F(m)$ be density function and cumulative rail failure distribution, respectively. Therefore, we have,

$$
\begin{gathered}
F(m)=1-\exp \left(-(\lambda m)^{\beta}\right), \\
f(m)=\frac{d F(m)}{d m}=\lambda \beta(\lambda m)^{\beta-1} \exp \left(-(\lambda m)^{\beta}\right),
\end{gathered}
$$

where $\beta$ is the shape parameter distribution and $\lambda$ is the inverse of characteristic function for the Weibull distribution with $\lambda>0$ and $\beta>1$. Using Eq. (1) and Eq. (2), $\Lambda(m)$ can be defined as follows,

$\Lambda(m)=\frac{f(m)}{1-F(m)}=\frac{\lambda \beta(\lambda m)^{\beta-1} \exp \left(-(\lambda m)^{\beta}\right)}{1-\left(1-\exp \left(-(\lambda m)^{\beta}\right)\right)}=\lambda \beta(\lambda m)^{\beta-1}$.

When there is a failure in some part of a rail, we may either replace or repair the part. Since the replaced part is only a small part of total rail, the replaced part can be ignored in Weibull function. The proposed model of this paper considers three cost components of inspection, preventive and corrective maintenance and the cycle of maintenance is terminated when the usage of rail reaches to $L$ in terms of MGT. The proposed model of this paper considers preventive maintenance and it looks for any possible failure. Fig 1 shows the interval of preventive maintenance, which increases the reliability and reduces the rate of failure. We may have some corrective maintenance between each preventive maintenance.

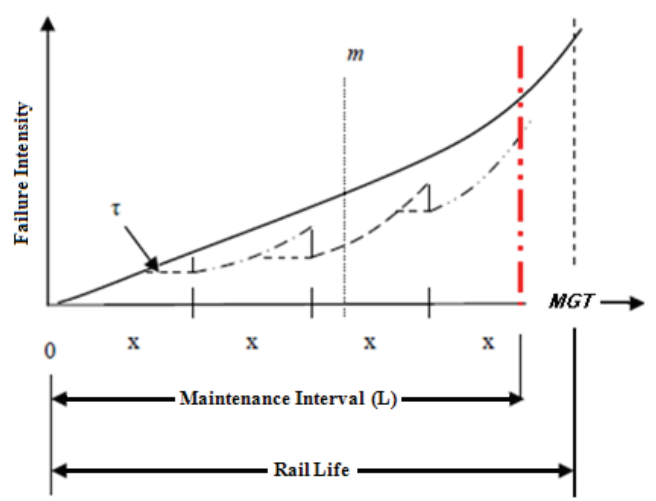

Fig. 1. Proposed maintenance model 
In Fig. $1 \tau$ represents age restoration after each preventive maintenance, which can defined as follows,

$\tau=\alpha \cdot x$,

where $\alpha$ is a quality of preventive maintenance, which is between zero and one. A value of zero means preventive maintenance has no impact on the rail and it is as bad as old. A value of one represents a perfect maintenance operation, which brings the rail to a good condition or as good as new. The following assumptions are made to simplifies the proposed model of this paper,

- The rate of failure is a non-decreasing function of time,

- Corrective maintenance covers rail replacement and minimal repairs,

- Preventive maintenances are executed in constant time cycles in every $x$ MGT,

- Any preventive maintenance improves overall conditions of rail,

- Any increase in level of restoration depends on the quality of maintenance,

- All cost components during the preventive maintenance is constant and it is assumed to be $L$.

The proposed model of this paper consider the total cost of maintenance $\left(C_{T}\right)$ is as follows,

$C_{T}=C_{m}+C_{i}+C_{r}$,

where $C_{i}$ and $C_{r}$ are the costs of inspection and risk associated with unexpected accidents, respectively and $C_{m}$ is the cost of maintenance, which is defined as follows,

$C_{m}=C_{p m}+C_{c m}$

where $C_{p m}$ is the cost of preventive maintenance, which consists of grinding and lubrication. In addition, $C_{c m}$ is associated with corrective cost items such as welding process, grinding, etc. The failure intensity considering preventive maintenance is defined as follows,

$\Lambda_{\mathrm{pm}}(m)=\Lambda(m-k \tau)$

where $k$ is the number of maintenance operations until time $m$. Therefore the rate of failure $(F R)$ is as follows,

$F R=\int_{k x}^{(k+1) x} \Lambda(m-k \tau) d m$

In order to calculate total number of failure we have,

$F R_{T}=\sum_{k=0}^{N+1} \int_{k x}^{(k+1) x} \Lambda(m-k \tau) d m$,

where $N$ is the number of preventive maintenance. Let $C_{l c m}$ be the cost of corrective maintenance per meter and $L e$ be the length of rail. Total cost of corrective maintenance is calculated as follows,

$$
C_{c m}=C_{1 c m} * L e * \sum_{k=0}^{N+1} \int_{k x}^{(k+1) x} \Lambda(m-k \tau) d m .
$$

The total cost of preventive maintenance is calculated as follows, 
$C_{p m}=N * L e * C_{1 p m}$

where $C_{1 p m}$ is the cost of preventive maintenance per meter. So, total inspection cost is defined as follows,

$C_{i}=N_{i} * L e * C_{1 i}$

where $C_{l i}$ is the cost of inspection per meter and $N_{i}$ is the the number of preventive maintenance, which is forecasted and it is calculated as follows,

$N_{i}=\left[\frac{L}{I_{f}}\right]$,

where $I_{f}$ is the optimal inspection interval. The cost associated with the risk of unexpected incidents is as follows,

$C_{r}=E[N(L)] \times\left[P_{n}(B) \cdot b+\left(1-P_{n}(B)\right) \cdot\left(P_{n}(A)\right) \cdot a\right]$,

where $\alpha$ is the cost of each unexpected accidents, $b$ is the cost of repairing potential failure using ultrasonic sound waves, $P_{n}(A)$ is the probability of potential failure leading to accidents, $P_{n}(B)$ probability of detecting potential failures using ultrasonic sound waves and $E[N(L)]$ is the expected number of failures. Therefore, the total cost is calculated as follows,

$$
\begin{gathered}
C_{T}=\left\{\left[C_{1 c m} \cdot \sum_{k=0}^{N+1} \int_{k x}^{(k+1) x} \Lambda(m-k \tau) d m\right]+N \cdot C_{1 p m}\right\} * L e+\left[\left(\frac{L}{I_{f}}\right) \cdot C_{1 i}\right] * L e \\
+\left(E[N(L)] *\left[P_{n}(B) \cdot b+\left(1-P_{n}(B)\right) \cdot\left(P_{n}(A)\right) \cdot a\right]\right)
\end{gathered}
$$

\section{The results}

In this section, we present the details of the implementation of our proposed model on railroad transportation of Iran. We gathered statistical information of railroad activities between 2006 and 2007. MATLAB toolbox optimization is used to generate maximum Likelihood (MLE) estimator to measure the values of $\lambda$ and $\beta$. Fig. 2. Shows details of the operational MGT generated by MATLAB.

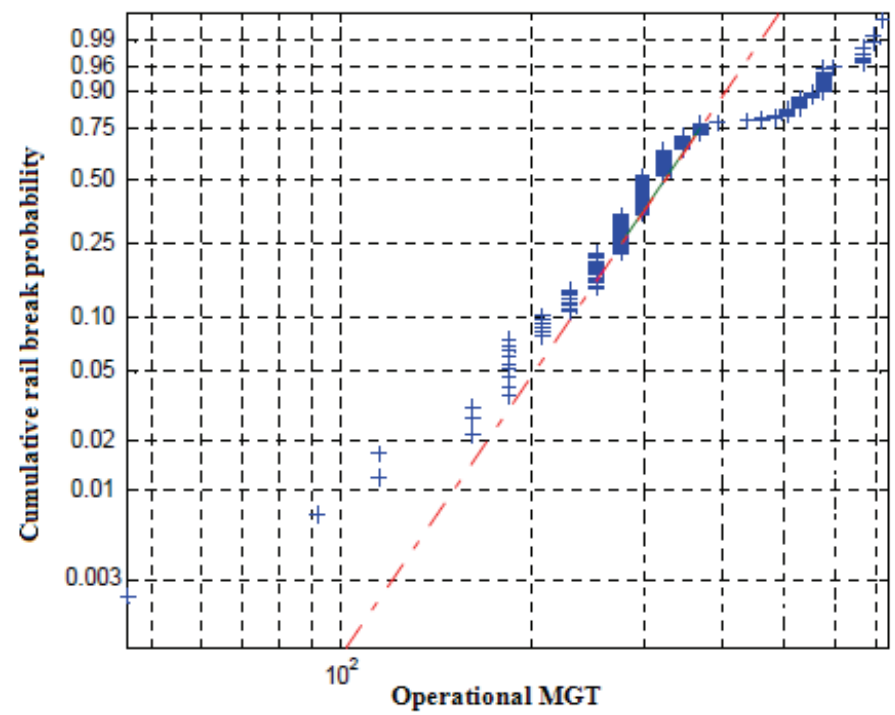

Fig. 2. MATLAB generated Weibull graph for rail failure data 
Table 1 shows details of the costs and MGT in two years of 2006 and 2007.

Table 1

Details of track length, MGT and maintenance cost in terms of local currency

\begin{tabular}{llll}
\hline Year & Track length $(\mathrm{KM})$ & MGT & Maintenance cost $\left(\right.$ Rials $\left.\times 10^{6}\right)$ \\
\hline 2006 & 901 & 42.8 & 11736.75 \\
2007 & 930 & 43.3 & 12562.50 \\
\hline
\end{tabular}

The cost includes the necessary surface welding, replacement of rail, inspection of rail, lubrication of rail and other overhead expenditures. Fig. 3 shows details of the results of our proposed model compared with what real-world case study.

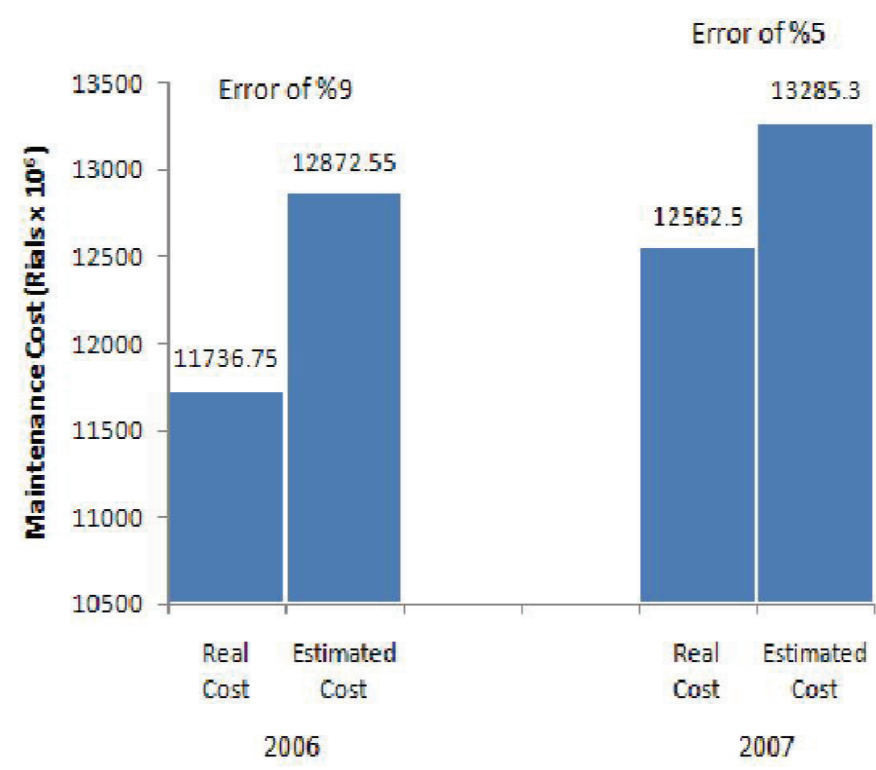

Fig. 3. Real and estimated maintenance costs

The reason for having errors in our computation could be because of the existence of the cost of risk associated with the proposed model. Note that there was no incident during the years of our investigation. The difference between the errors in two consecutive years can also be described for the nonlinear behavior of the proposed model.

\section{Conclusion}

In this paper, we have presented an improved mathematical model for managing the cost of rail maintenance. The proposed model of this paper considers a Weibull distribution for failure intensity function and different expenditure of inspection, corrective, etc. The proposed model has been implemented for a real-world case study of railroad industry of Iran using the data of the years of 2006 and 2007. The preliminary results indicate that the proposed model of this paper can predict the cost of maintenance with an acceptable error. The proposed model of this paper can be extended with some additional real-world assumptions such as considering the cost of interruption of a traffic for the failure and we leave it as a future work for interested researchers.

\section{Acknowledgment}

This paper was financially supported by center of research of Iranian railroad company under grant number 23/3752 dated March, 2011. 


\section{References}

Cannon, D. F., Edel, K.O., Grassie, S. L., \& Sawley, K. (2003). Rail defects: an overview. Fatigue \& Fracture of Engineering Materials \& Structures, 26, 865-886.

Hargrove, M.B. (1985). Track maintenance cost analysis: An engineering economics approach. Transportation Research Record 1029, Transportation Research Board, National Research Council, National Academy Press, Washington, D.C., USA, 64-70.

Ebersohn, W. (1997). Track maintenance management philosophy, Proceedings from $6^{\text {th }}$ International Heavy Haul Railway Conference, 6-10 April, Cape Town, South Africa, 784-795.

Esveld, C. (2001). Modern railway track, Delft: MRT-Productions. 2nd edition, Germany.

Jendel, T. (1999). Prediction of wheel and rail wear, TRITA -FKT Report 2002:22, ISSN 1103470X, ISRN KTH/FKT/FR - 02/22 - SE, Royal Institute of Technology, Railway Technology, Sweden.

Magel, E., \& Kalousek, J. (2002). The application of contact mechanics to rail profile design and rail grinding. Wear, 253(1-2), 308-316.

Reddy, V., Chattopadhyay, G., \& Larsson-Kraik, P.O. (2007). Modelling and analysis rail maintenance cost. International Journal of Production Economics, 105, 475-482.

Chattopadhyay, G., Kumar, S., Larsson-Kråik, P.O., \& Kumar, U. (2006). Estimation of parameter for degradation of rails, Proceedings of 19th International Congress on Condition Monitoring and Diagnostic Engineering Management, Luleå, SWEDEN, 12th -15th June, $605-612$.

Lichtberger, B. (2005). Track Compendium. Eurailpress, Tetzlaff-Hestra GmbH \& Co., $1^{\text {st }}$ ed., Hamburg, Germany. ISBN 3-7771-0320-9.

IHHA (International Heavy Haul Association), (2001). Guidelines to best practices for heavy haul railway operations: wheel and rail interface issues. International Heavy Haul Association, May, Virginia, USA. 